\title{
Research on Motives and Feasibility of Outsourcing Internal Auditing
}

\author{
Yuexin Shi \\ School of Economics and Management \\ Nanjing University of Science and Technology \\ Nanjing, China
}

\begin{abstract}
Outsourcing behavior of internal auditing originated from the western countries. With the vigorous development of outsourcing industry and the change of enterprise operation demand, the internal auditing outsourcing model is gradually adopted by managers in Chinese enterprises. The eight parts of this paper focus on analyzing the motives of outsourcing behavior of internal auditing, and then take KPMG as an example to introduce the content and form of internal auditing outsourcing service provided by external contractors, and further prove the feasibility of the internal auditing service that is undertaken by external agencies, and finally suggest that enterprises still need rational judgments in the outsourcing decision-making, should not be too blind.
\end{abstract}

Keywords-internal auditing; outsourcing; motives; feasibility; KPMG

\section{INTRODUCTION}

In recent years, corporate governance has gradually become the focus of attention of managers in Chinese enterprises. Since the "Enron incident" broke out, more and more managers have focused their attention on internal auditing activities. With the continuous change of the internal management needs and the development of the concept of corporate governance, the internal auditing function is not only the supervision and evaluation in the traditional sense, but gradually provides consultation and confirmation services and risk control, which can increase the enterprise value for the enterprises' strategic direction

For many small or medium-sized enterprises and new enterprises, they usually do not have enough manpower and resources to set up internal auditing department in companies. For large enterprises, setting up internal auditing department may be difficult to achieve internal resources. Therefore, based on the advantages of improving the core competitiveness and cost saving, the outsourcing model of internal auditing comes into being and has been widely adopted by enterprises' managers.

\section{RELATED CONCEPTS AND DEFINITIONS}

\section{A. Definition of Internal Auditing}

Correction and improvement of the concept of internal auditing has experienced a long development process, its intention is to help managers to supervise business activities of organizations. With the development of corporate governance theory and the changes of enterprise practice needs, the internal auditing function is gradually expanded, so the purpose of internal auditing has gradually changed from the original business management orientation to the risk oriented internal auditing, and the scope of internal auditing work extends from the traditional supervision and evaluation to consultation and confirmation services.

\section{B. Externalization of Internal Auditing}

Internal auditing outsourcing (externalization of internal auditing), refers to the part or all functions of an enterprise's internal auditing, which is entrusted to the outside of the enterprise by contracting, and is carried out by a more professional organization or staff. Along with the changing global economic environment, enterprises find that the competitive situation they faced is more serious. The internal auditing outsourcing is a form of business, which is as a way to reduce the cost and achieve the optimal allocation of resources, so naturally it becomes the optimal strategy choice of many enterprises which aim to develop their own competitive advantages.

\section{THE ANALYSIS OF MOTIVES OF INTERNAL AUDITING OUTSOURCING}

\section{A. Motives Analysis Based on Transaction Cost Theory}

In 1937, Ronald H. Coase proposed that market is based on price adjustment to achieve the allocation of resources, but the enterprises are through internal authority in order to realize the allocation of resources, and decisions depend on the number of transactions consumed in the two kinds of mechanisms in the trading activities [1]. The decision of internal auditing outsourcing is actually to make a choice in the two control mechanisms of enterprises and market, when enterprises produce management and coordination costs which are greater than transaction costs of external personnel, firms tend to outsource the transaction to the market.

\section{B. Motivation Analysis Based on Core Competence Theory}

According to the theory of core competence, the companies are composed of two parts: resources and capabilities [2]. Scarce resources or special ability owned by firms are determining factors for enterprises to have competitive 
advantages and achieve strategic objectives. That is, the core competitiveness. Outsourcing non-core business is an effective way for enterprises to realize their core competitiveness.

Internal auditing is usually regarded as a regulatory mechanism to enterprises, and provides non-core business services for enterprises. In order to concentrate the limited resources on the core business, enterprises are more inclined to transfer their internal auditing services to external professional organizations. Therefore, it is also one of the motives of outsourcing internal auditing to concentrate resources and develop core competence.

\section{Motivation Analysis Based on Principal Agent Theory}

The emergence of agency problem originates from the separation of enterprise ownership and enterprise management right. The top managers in enterprises play two roles: they are trustees for the outside of the enterprises with external accountability, responsible for business owners. At the same time, in order to ensure overall stable operation of the enterprises, top managers also acts as the identity of clients in the enterprises, they entrust relatively independent third parties to prove that they have accountability [3.4]. Therefore, outsourcing behavior of internal auditing can also be explained by agency theory, that is, outsourcing of internal auditing is an extension of internal fiduciary relationship. Outsourcing will become a natural choice when outsourcing can reduce more agency costs and adds more value to the enterprises than the internal auditing departments in firms.

\section{FEASIBILITY ANALYSIS OF INTERNAL AUDITING OUTSOURCING}

\section{A. Feasibility Analysis Based on Contractos' Perspective}

1) The Competency of Auditors in External Agencies: Whether external practitioners have the ability and qualification to engage in internal auditing activities is a decisive factor of internal auditing outsourcing. Internal auditing outsourcing services are generally carried out by experienced auditors with CPA, ACCA or other professional qualification certificates, and they have accumulated a wealth of work experience and business skills in many industry areas. Practitioners may also use their accumulated experience and knowledge to effectively implement auditing functions, even if they confront with a lack of understanding in the internal auditing work.

2) Development needs of external institutions: The appearance of internal auditing outsourcing service has widened the scope of business and profit space for accounting firms and other external organizations. Undertaking the internal auditing service from companies will increase the profit margin of accounting firms and reduce their dependence on the single external auditing revenue. In addition, acceptance of internal auditing services will undoubtedly urge the professional auditors to broaden their thinking, and constantly dabble in advanced production, operation and management concepts at home and abroad, and expand the professional knowledge system. Therefore, whether for enterprises or accounting firms, externalization of internal auditing can become a win-win strategic choice.

\section{B. Feasibility Analysis Based on Enterprises' Perspective}

1) The inevitable choice of ensuring the independence of internal auditors: When the internal auditing activities are undertaken by the external service institutions, they are only responsible for the clients and the public. In addition to providing audit services commission for outside organizations, and there have no other profitable relationships. In this case, auditors' independence will be greatly improved and corporate executives can obtain more authentic information from the work of internal auditors. At the same time, it also helps to outside investors and other stakeholders transfer information about that they pay much attention to the management and supervision of enterprises, improve the corporate image and credibility in the minds of investors and which will bring positive influence to the daily management and financing behaviors.

2) The only way to improve the quality of internal auditing: Compared to the internal employees, accounting firms and other external professional organizations has reserved a large number of experienced professionals, who have a keen insight into the potential risks and defects in the management of enterprises, so the internal auditing function will be more effective. For the new enterprises and small or medium enterprises, enterprises will apply domestic and foreign advanced management methods and experience to their own operation under the help of external professionals, with the help of experienced external experts they will quickly integrate into the local culture, and set long-term strategic plan for enterprises development.

3) The necessary guarantee to reduce enterprise cost:If enterprises have internal auditing department, they will inevitably face continuing costs and expenses, enterprises often need to invest a lot of training cost regularly, in order to ensure that internal auditors' knowledge concepts can keep pace with times. In contrast, when the internal auditing function is outsourced, the cost of internal auditing becomes the more flexible business expense. Due to competitive market where competition external agencies provide outsourcing services, enterprises will be beneficial, through using market resources allocation function to get reasonable prices and reduce corporate expenses.

\section{CONTENT AND FORM OF OUTSOURCING INTERNAL AUDITING—TAKING KPMG AS AN EXAMPLE}

KPMG has a long history, and its development across three centuries, including consulting services, audit services and tax services business. According to the "KPMG International Annual Review in 2016" statistics, KPMG had nearly 189,000 full-time employees and achieved an annual income of 25420 million dollars in 2016 fiscal year.

According to KPMG's official website, the internal auditing departments of risk management and compliance services include more than 4800 professionals in 2009, which shows an increasing trend in recent years, more and more partnership 
firms focus on the consulting business, and the internal auditing service is an important branch of management consulting services, so this paper will take KPMG as an example to explain that the work and scope of the internal auditing service provided by the external contractors.

\section{A. The Level of Corporate Governance -- Compliance Consulting Service}

Currently, compliance requirements for corporate governance by local regulators are a problem faced by many enterprises, while internal auditors of KPMG can review functions of enterprise operation, compliance, finance and risk management, and utilizes global resources and the actual situation of the enterprises' internal control to assist enterprises to meet the compliance requirements, and create great value for enterprises.

\section{B. Risk Management Level}

1) Overall business risk assessment:As an internal auditing service provider, KPMG introduces a new approach about risk assessment, that is, comprehensive business risk evaluation method, in order to help enterprises identify potential risks. In this way, KPMG practitioners will summarize the problems faced by enterprises, and order the management risks according to the severity and probability of occurrence, so as to make companies' managers fully aware of potential risks, help them properly allocate enterprise resources, and efficiently put energy to the most critical areas of risks.

2) Self-assessment of internal control and risk:Internal auditing, risk management and compliance service departments of KPMG have professionals with working experience, who can evaluate and review the activities for enterprises, assist the enterprise with developing and implementing of cost-effective control and risk management system, help enterprises to achieve business quality objectives. Under this kind of service, KPMG adopts a highly cooperative approach, that is, cooperating with the senior management or the internal auditing team to provide strategic advice for the enterprises.

\section{Internal Auditing Activity Level}

1) Key performance indicators setting:Nowadays, more and more enterprises are keen to use the internal auditing function to measure the key success factors of enterprises (such as business process efficiency, enterprise innovation ability) in macro sense with measurable key performance indicators. $\mathrm{KPMG}$ as one of the four main international firms, because business personnel are familiar with all kinds of professional skills and auditing standards, which can help enterprises transform personnel, processes and positioning to meaningful business indicators, and then adds strategic value to internal auditing function.

2) Establishment of internal auditing function:KPMG has strong internal auditing, risk management and compliance services department, and its professional team has closely cooperate with private enterprises or the public sectors all walks of life (such as finance, automotive, construction and real estate, insurance, telecommunications, health care), and has very rich experience on the internal auditing strategy, risk evaluation, human resources planning and recruitment. At the same time, KPMG demonstrates standard internal auditing practices, and also provides internal auditing training for the corporates' audit departments. Such services apply to enterprises that have already set up internal auditing departments, or managers who are dissatisfied with the functions of internal auditing.

3) Continuous audit and continuous monitoring: Continuous auditing mechanism can enable enterprises to quickly identify exceptions, abnormal and inconsistent factors, as well as effectively analysis risky data. Continuous Monitoring can provide near real-time information, key performance indicators to predict future developments for managements, so that managers can grasp the best opportunity to control risk. The work of this service includes: firstly, evaluate and design the overall implementation plan; secondly, evaluate risks and design query protocols and reports; thirdly, evaluate software tools and make recommendations; fourthly, perform continuous auditing; fifthly, command change management process; sixthly, make recommendations on reporting and dashboard functions; seventhly ,train management and internal auditors. In order to meet the specific needs of enterprises' customers, core service teams of KPMG coordinate with team members in order to achieve strategic deployment according to specific circumstances.

According to the above internal auditing service content and outsourcing mode, the function of internal auditing can be deeply explored in the external institutions. This shows that KPMG, as an external contracting agency, has expertise and advanced management skills to provide outsourcing services, which can bring a lot of additional value to the internal auditing function.

\section{RISKS OF INTERNAL AUDITING OUTSOURCING}

\section{A. Deviation of Internal auditing Function}

In recent years, the function of internal auditing has gradually changed from "supervision orientation" to" service orientation ", and its economic performance has increased. In order to maximize profits, the accountant may consider it as a procedural work in the course of providing service and only fulfill the stipulated obligations in the contract without further exploration. When internal auditing is regarded as a profit channel for external institutions, internal auditing function is easy to be weaken or even fail.

\section{B. Unfavorable to Internal Control Integratio of Companies}

Internal auditing as an important function, when outsourcing it, on the perspective of corporate governance, identity of managers varies from "corporate steward" to " corporate helpers". Managers participation will be weakened, which reduces the effect of corporate governance. Therefore, the externalization of any function may lead to the lack of the internal control system. 


\section{RISK AVOIDANCE OF INTERNAL AUDITING EXTERNALIZATION}

\section{A. Overall Analysis of Outsourcing Risk}

The outsourcing of internal auditing will bring some uncertainties to firms, such as external institutions which may rely on internal information of enterprises raise commissions and charge fees. In addition, there have adverse selection, be difficult to estimate cost and be lack of qualifications for external personnel in the internal seek phases of audit outsourcing services, which leads to significant losses and leakage of business secrets within the enterprises. Therefore, whether choose the internal auditing outsourcing or not, companies still need to combine the specific content and scope of internal auditing work, and have comprehensive analysis of possible transaction cost as well as according to the costbenefit principle carefully make outsourcing decision.

\section{B. Reasonable Choice of Outsourcing Model}

In the course of outsourcing decision-making, business which involves internal resources should be completed within the enterprises, but the conventional and universal business should be outsourced to professional institutions, such as compliance audit, the reliability of accounting information audit. At the same time, companies should also reasonably predict the frequency of the transaction. With the optimization of the internal auditing function and the increasing attention of managers and other shareholders, the transaction frequency of internal auditing activities may rise. Accordingly, enterprises should choose outsourcing programs according to their own circumstances, such as cooperative internal auditing, audit management consulting or setting up the internal auditing departments.

\section{Perfect Outsourcing Contract and Balance Service Charge}

First of all, enterprises should try to select qualified and strong outsourcing institutions to ensure the quality of service to meet the requirements; secondly, enterprises should balance the service fees according to the companies' own situation.

If the service charge is too low, it may cause the external agencies to narrow the scope of audit and send the auditors with insufficient qualifications, which will eventually lead to the failure of auditing functions. On the contrary, if the agreed service fee is too high, it is not in accordance with the principle of cost-benefit. In addition, when signing outsourcing contracts, the enterprises should make the written agreement as far as possible in terms of the content and scope of outsourcing services and the evaluation standards of service performance, improve the outsourcing contract, clear the power and responsibility, and reduce the opportunistic behavior and outsourcing risk later.

\section{CONCLUSION}

To sum up, no matter from the theoretical research level, the supply and demand sides of the market, or the actual operation level, outsourcing internal auditing is feasible.
However, since the enterprises are able to benefit from the function of internal auditing outsourcing, the outsourcing process still contains many risks and defects, so enterprises still need to weigh their own operating conditions, think about the enterprises' intrinsic motivation of outsourcing and demand, and then make rational outsourcing decision-making, and be careful to avoid outsourcing risks.

\section{REFERENCES}

[1] Coase. R., The Nature of the Company, Economic Thought Journal, pp.32-49, June 2003.

[2] Prahalad C K, Hamel G. The Core Competences of the firms [J], Harvar d Business Review, 1990, 66:79-91.

[3] Jensen, M. C., Meckling, M.H.. Theory of the Firm: Managerial Behavior, Agency Costs and Owner-ship Structure. Journal of Financial Economics, 1976, 3(4): 305-360.

[4] Chen Hui, Research on Outsourcing of Internal Audit of Small and Medium Enterprises in China, Shanxi University of Science and Technology, 2014.

[5] International Internal Inspection Association, Standards of Internal Auditing Practice, China Times Economic Press, 2003. 